\title{
Contributions of Annex SL to Corporate Sustainability
}

\author{
Thaís Vieira Nunhes, Thalita Láua Reis Campos, Fernanda Ellen Francisco and \\ Otávio José de Oliveira*
}

Department of Production, São Paulo State University-UNESP, Guaratinguetá, Brazil

\section{OPEN ACCESS}

Edited by:

Gillberto Santos,

Instituto Politécnico do Cávado e do

Ave (IPCA), Portugal

Reviewed by:

Ryosuke Yokoi,

National Institute of Advanced

Industrial Science and Technology

(AIST), Japan

Edwin Samir Pinto Maquilon,

University of Zaragoza, Spain

*Correspondence:

Otávio José de Oliveira

otaviodeoliveira@uol.com.br

Specialty section:

This article was submitted to

Quantitative Sustainability

Assessment,

a section of the journal

Frontiers in Sustainability

Received: 21 July 2021 Accepted: 29 September 2021

Published: 26 October 2021

Citation:

Nunhes TV, Campos TLR,

Francisco FE and Oliveira OJd (2021)

Contributions of Annex SL to

Corporate Sustainability.

Front. Sustain. 2:745350

doi: 10.3389/frsus.2021.745350
With the advance of globalization and population increase, it was necessary to intensify the production of goods to meet the new demands that arose. As a result, a significant emergence of negative socio-environmental impacts was observed, affecting the entire planet. The UN launched the 2030 Agenda to encourage all sectors of the economy, including the industrial sector, in promoting Sustainable Development (SD). Companies have sought to adopt techniques, tools and practices that enable SD in organizations. Among the range of possibilities to operationalize sustainable management, there are the Certifiable Management Systems (CMSs) ISO 9001, ISO 14001, and ISO 45001. In order to facilitate the integration between these systems, ISO launched in 2018 the Annex SL with the High-Level Structure (HLS), providing greater compatibility between them. However, most companies do not know enough about this change and its benefits for sustainability. Thus, this work presents the main contributions of Annex SL to the development of sustainability in companies that have implemented CMSs. By reviewing the literature on the relationship between CMSs and sustainability, and the expertise of the authors, it was possible to identify and discuss on the contributions of the main elements of the HLS to sustainability, which are organizational context analysis, risk management, evidence-based decision making, emphasis on measuring and evaluating processes and results, and a culture of integration and continuous improvement.

Keywords: sustainability, sustainable development, management systems, integrated management systems, Annex SL

\section{INTRODUCTION}

The population growth has driven manufacturing operations that enhance climate change, carbon dioxide emission, and occurrence of health and natural disasters. In 2015, the UN launched the 2030 Agenda with the objective of helping all sectors of the economy in mitigating these and other negative impacts, promoting the Sustainable Development (SD) of the planet (Ikram et al., 2021). The idea of SD was first presented in the open letter of the World Commission on Environment and Development (WCED), which defines the term as "the development that meets present needs without compromising the ability of future generations to meet their own needs" (WCED, 1988) being promoted by a set of global, regional, and local initiatives that meet these demands (Nunhes et al., 2020).

In order to operationalize the SD, the term Triple Bottom Line (TBL) was created in 1990, proposed by the business consultant John Elkington to describe the added values that economic, social and environmental aspects can bring to business. The TBL framework aims to develop policies and strategies to generate profit and income that promote the fair development of society 
and the use of natural resources in accordance with the planet's natural regeneration capacity, considering the balance between the dimensions "people, profit, and planet" (Hammer and Pivo, 2017; Sajan et al., 2017).

One of the sectors of the economy that generates significant negative impacts on the SD is the industry, which must meet new and demanding requirements in order to survive in the global market. These demands generate negative socioenvironmental effects such as increased emissions of polluting gases, depletion of natural resources, use of materials, and products harmful to human health, excessive increase in working hours, etc. (Aboelmaged, 2018). To mitigate these effects, companies have been seeking operational, technological and managerial improvements that enable them to survive and evolve in the short, medium and long term, taking into account the minimization of impacts on the environment and the wellbeing of society (Oliveira, 2013; Lozano, 2015). Researchers and organizations have developed solutions to mitigate the negative impacts that current business activities and strategies generate on the planet's sustainability (Johnson and Schaltegger, 2016). In the business context, SD involves actions that respect human beings, society in general and the environment. For a company to be considered economically, socially and environmentally sustainable, it must adopt ethical actions and procedures that allow its economic growth with the least possible impact on the environment and that promote the development of society (Sharma et al., 2021).

The development of sustainability in the business environment requires the use of sustainability management instruments, concepts and systems, such as eco-efficiency analysis, life cycle assessments (LCAs), Quality Management Systems (QMS), Environmental Management Systems (EMS), Occupational Health and Safety Management Systems (OHSMS), Social Responsibility Management Systems (SRMS), sustainability reports and indexes, social and environmental audits, among others (Johnson and Schaltegger, 2016). Sustainability management supports managers in a variety of roles aimed at reducing negative economic, social and environmental impacts and managing positive impacts, while allowing for keeping the company competitive and successful (Johnson and Schaltegger, 2016). Sustainability management can be implemented in various areas of companies, such as sustainable manufacturing, which helps to create products that use minimal resources, minimize negative impacts on the environment and ensure an affordable cost for society. Thus, companies need to change the traditional (linear) production model to sustainable production and incorporate the SD theme into their agendas, directing them to an organizational strategy

\footnotetext{
Abbreviations: CMSs, Certifiable Management Systems; EMS, Environmental Management System; FMEA, Failure Mode Effect Analysis; HLS, High-Level Structure; IMS, Integrated Management System; ISO, International Organization for Standardization; MS, Management Systems; OHSMS, Occupational Health and Safety Management Systems; QMS, Quality Management System; RM, Risk management; SD, Sustainable Development; SRMS, Social Responsibility Management Systems; TBL, Triple Bottom Line; WCED, World Commission on Environment and Development.
}

that contributes to the sustainability of the planet (Hsu et al., 2017).

Thus, the SD needs to be present in activities throughout the product's life cycle, from its conception to its proper disposal. This allows the negative effects arising from the use of the product on natural resources and on stakeholders such as consumers, employees, communities to be minimized (Aboelmaged, 2018). To assist in the implementation of SD, various management systems (MS) can be used to improve performance and help the company grow in its economic, social, and environmental elements. For this, certifiable management systems (CMSs) are commonly used, such as the QMS (ISO 9001), the EMS (ISO 14001), the OHSMS (ISO 45001) (Dahlin and Isaksson, 2017; Ribeiro et al., 2017; Benyettou and Abdellatif, 2018). However, the development of these MSs separately generates additional costs, wasted time and resources, and inefficient and bureaucratic processes that hinder the continuous improvement desired with their implementation. Thus, the Integrated Management System (IMS) emerged, which is a set of interrelated processes with the objective of developing the organization from the shared use of resources from the various CMSs (Nunhes et al., 2017, 2019; Ribeiro et al., 2017; Moumen and Elaoufir, 2018). To facilitate the integration of CMSs, ISO created in 2012 the Annex SL with the High-Level Structure (HSL).

However, most companies do not have sufficient knowledge about the changes that Annex SL has brought to CMSs and, consequently, are unaware of the potential contributions of these changes to the development of sustainability (Anttila and Jussila, 2017; Rybski et al., 2017). Therefore, the objective of this work is to identify the main contributions of Annex SL to the sustainability of companies that have implemented CMSs. This work was developed based on a careful literature review on the relationship of CMSs with sustainability. For this, peerreviewed scientific articles published in the Scopus database until June 2021 were selected. Further, the CMSs standards, guidelines for developing them and Annex SL were analyzed in light of recent literature and based on the authors' experience, with the aim of achieving the objective proposed in this work. After this introduction section, the text follows with the presentation of the theoretical framework that supported the analyzes presented in the results and discussions section.

\section{THEORETICAL FRAMEWORK}

Sustainability has been recognized as an important competitive advantage, consequently, investments to achieve it have increased in companies. Improving the management and performance of processes arising from the implementation of sustainable practices is an opportunity for the company's development and growth. Its benefits can improve labor relations, attract more qualified, and diverse human resources and mitigate socioeconomic and financial risks as well as stakeholder pressures commited to SD (Hsu et al., 2017).

Achieving these benefits requires the balanced development of actions for economic, social, and environmental sustainability. These three pillars of TBL allow the operationalization of 
the sustainability strategy in companies (Hammer and Pivo, 2017; Sajan et al., 2017). In the economic pillar, actions that intensify the economic prosperity of the company and of society as a whole are promoted through decision-making that favors SD. The development of this pillar involves responsible investment, definition of strategies and governance committed to sustainability (Lopez-Cabrales and Valle-Cabrera, 2020). In the social pillar, strategies are developed that facilitate society's access to basic resources for a dignified survival with health, safety and education. Aiming to promote integration and social equity, companies can develop actions to value diversity and equal opportunities, health and safety at work, ethical and transparent behavior, philanthropy and social assistance to the community in which they operate, among others. And in the environmental pillar, actions are developed to minimize the negative ecological impacts on the planet from production activities, such as reducing the consumption of products that are toxic to the environment, using natural resources as consciously as possible, containing pollution, properly disposing of waste, etc. (LopezCabrales and Valle-Cabrera, 2020; Stefaniec et al., 2020).

In order to satisfy the needs of interested parties, including sustainable management, and to promote the continuous improvement of their processes, many companies have resorted to different management systems such as the QMS, EMS, and OHSMS (Majerník et al., 2017; Nunhes et al., 2019). Focusing on market needs, the International Organization for Standardization (ISO) brings together experts from around the world to share knowledge and develop international standards for management systems as shown in Figure 1 (ISO, 2021).

Among the various standards developed by ISO, the most used by organizations are ISO 9001 (Quality Management), ISO 14001 (Environmental Management) and ISO 45001 (Occupational Health and Safety Management) (Majerník et al., 2017). As can be seen in Figure 1, these standards contribute to the SD on the three pillars of the TBL. For example, in the economic pillar, ISO 9001 is a reference standard for the QMS, which helps managers to standardize and improve products, services and processes, taking into account sustainability, reducing variability and meeting customer needs (Ismyrlis and Moschidis, 2015).

In the social pillar, ISO 45001 helps managers to promote worker safety when performing their work activities. This

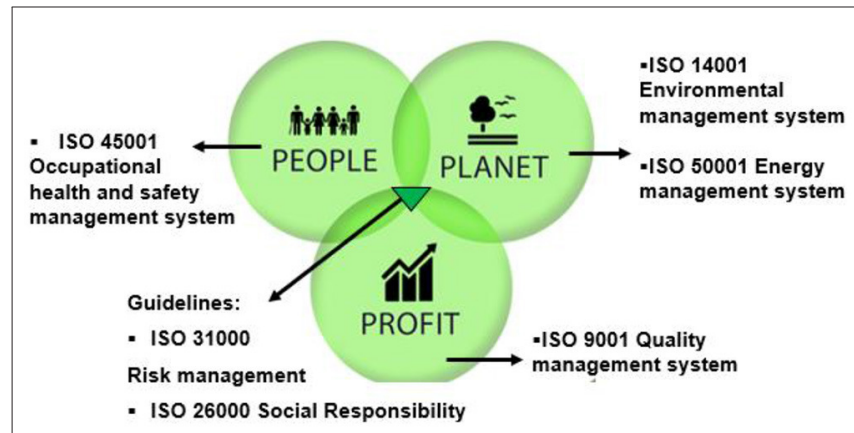

FIGURE 1 | Relationship of ISO Certifiable Management Systems with the TBL. Source: Based on Nunhes et al. (2020). standard is intended to help organizations comply with applicable legal requirements and provide healthy conditions to protect the occupational health and safety of their employees. ISO 45001 replaced OHSMS 18001 (occupational health and safety management system) to better adapt it to the market reality, having been published in accordance with the structure of Annex SL, which facilitates integration with the latest versions of the standards certifiable from ISO management systems, such as ISO 9001 and ISO 14001 (Domingues et al., 2015; Kafel, 2016). In the environmental pillar, ISO 14001 is a reference standard for the implementation and development of the EMS, which encompasses the establishment of environmental policies, actions and plans. This standard helps organizations to seek a balance between developing and minimizing negative environmental impacts on society in general (Domingues et al., 2015; Kafel, 2016). ISO 50001 also makes contributions to the environmental pillar of sustainability, as it has requirements to facilitate the efficient energy management of companies, in addition to guidelines for the use of energy from renewable sources (Nunhes et al., 2020). In order to contribute more significantly to sustainability, it is possible to complement CMSs with ISO 26000 guidelines for the development of corporate social responsibility and ISO 31000 for the management of economic, social and environmental risks (Klute-Wenig and Refflinghaus, 2015; Nunhes et al., 2020).

The different structures of the CMSs made the implementation of the IMS difficult due to the lack of alignment between the standards that evolved independently over the years (Purwanto et al., 2020). ISO then created in 2012 the Annex SL, which has the HLS framework in order to facilitate this alignment and the integration of certifiable management standards. The HLS of Annex SL has been under review since 2019 in order to be replaced by Annex L. Compared to Annex SL, Annex L will bring improvements in its structure and terminology, in addition to analyzing whether some requirements such as leadership and emergency preparedness will be mandatory or not (Savino and Batbaatar, 2015; Majerník et al., 2017; Nunhes et al., 2019). ISO is expected to launch the final version of Annex L in 2021 (ISO, 2021). Annex SL has clauses and appendices that serve as the basis for the structure of the CMSs that are adopted by companies in search of better economic, environmental and social performance, minimizing the negative impacts of their actions on the planet and society (Savino and Batbaatar, 2015; Majerník et al., 2017; Nunhes et al., 2019).

This structure is divided into 10 items, namely: scope, normative references, terms and definitions, context of the organization, leadership, planning, support, operation, performance evaluation, and improvement (Majerník et al., 2017; Nunhes et al., 2019). Annex SL brought some changes and additions to the structure of CMS standards, some of which were the analysis of the organizational context, risk-based thinking, evidence-based decision making, greater emphasis on measuring and evaluating processes and results, and culture of integration (Fonseca and Domingues, 2017; Ferreira et al., 2019; Skład, 2019). Annex SL has been being revised since 2019, in order to improve the HLS structure and verify if some requirements are really feasible and necessary. Its final review is scheduled 
for 2021, when Annex SL should be renamed as Annex L (ISO, 2021).

\section{CONTRIBUTIONS OF ANNEX SL TO SUSTAINABILITY}

This section presents the contributions of Annex SL to Sustainability, identified from the literature review presented in section Theoretical Framework and the analysis of the main changes in the revised versions of the ISO CMSs and Annex SL.

\section{Analysis of the Organizational Context}

The analysis of the organizational context was inserted in the Annex SL structure in order to assess the socioeconomic factors that may affect the organization in the context of CMSs. The organization needs to be aware of all factors that can impact them, whether external factors, such as suppliers, government and customers, or internal, such as beliefs, values, employees, among others.

The analysis of the organizational context allows CMS managers to periodically update with events in the external environment that influence or may influence the execution of activities inherent to the systems. Given the relationship of CMSs to sustainability presented in the introduction to this work, the analysis of the organizational context can be used as input for sustainability performance analyzes (Fonseca, 2015; Susanto and Mulyono, 2017). In analyzing the organizational context, external and internal issues that affect the ability of CMSs to meet the needs and expectations of the organization and its stakeholders should be considered (Manders et al., 2016; Rybski et al., 2017; Fonseca and Domingues, 2018). This analysis should include the assessment of global, regional, and local conditions that may affect the performance of the CMSs, providing important inputs for the organization's sustainability in the short, medium and long term.

The analysis of the organizational context should include the analysis of the environmental TBL pillar, that is, the analysis of the environment in which the organization is inserted, highlighting the analysis of environmental legal requirements in force in the locations where it operates and the analysis of impacts and availability (in the present and in the future) of natural resources used in activities and processes. The analysis of the environmental context should be carried out by the EMS manager together with top management. The analysis of the organizational context in the social TBL pillar should involve several analyzes that demonstrate the impacts that the organization is generating on its internal and external stakeholders. All CMSs managers (or the IMS manager, if applicable), will be able to contribute by carrying out analyzes of the organizational climate and cultural alignment so that the results of the Sustainability strategy are more effective. Furthermore, all employees involved in the OHSMS has an important role in promoting the health, safety and well-being of employees. It is recommended that this essential care for people is passed on and charged to their customers and suppliers and, if possible, through the results of the analysis of the social context, that the surrounding community benefits from organizational social actions in areas such as nutrition, health, security, education, among others. Finally, the analysis of the organizational context in the economic pillar is a strategic analysis carried out by top management in which all those responsible for the CMSs can participate, so that the opinion of specialists in each TBL area and actual data from the organization are used as inputs for the analysis. The analysis of the economic context must consider the impacts of the aspects listed in all pillars of the TBL in order to seek the economic sustainability of the organization.

\section{Risk-Based Thinking}

The "risk-based thinking" was one of the modifications brought by Annex SL in the latest revisions of the ISO CMS standards. Risk management (RM) allows organizations to achieve their goals through diligent decision-making based on prior analysis of the risks to which the organization is exposed (Olechowski et al., 2016). The RM applied to CMSs enables the organization to identify, analyze and treat potential risks that may compromise the proper execution of its projects, processes or operations (Lalonde and Boiral, 2012). Risk analyzes referring to CMSs (ISO 9001, ISO 14001, ISO 45001) contribute to the organization's sustainability, as they will cover the identification, analysis and mitigation of economic, environmental and social risks. The enhancement of the "risk-based approach" element of the CMS standards can take place through the integrated analysis of the identified risks, so that the final analysis and treatments are given considering the interdependence between economic, environmental, and social risks. This means that failures in risk management in any of the three dimensions of TBL can cause damage to the CMSs and, consequently, to the organization itself and its stakeholders, compromising the transition to sustainability. Industrial companies generally focus on the control of environmental risks, therefore, greater attention to risk management on the social dimension of TBL is recommended. The OHSMS manager together with the human resources manager can support the management of social risks, extending the risk analysis to the external environment, for example, analyzing its relationships with its customers, suppliers, and the surrounding community. Some tools and methods that can be used to support RM and promote sustainability management in companies are SWOT analysis, FMEA (Failure Mode Effect Analysis) and Risk Matrix for operational risk assessment (Fonseca, 2015; Manders et al., 2016; Chiarini, 2017).

\section{Evidence-Based Decision Making}

The inclusion of the evidence-based decision-making requirement was another consolidated change in the latest revision of ISO CMS standards. According to the HLS of Annex SL, all decisions, regardless of the type or hierarchical level to which they refer, must be made based on reliable sources and information to achieve the expected results. This review endorses the need to assess and analyze all data available in the organization for the continuous improvement of the CMSs, with these analyzes being an important set of inputs for evidencebased decision-making on social and environmental aspects 
(Fonseca, 2015; Manders et al., 2016; Chiarini, 2017). Evidencebased decision making in ISO CMSs can help companies in the transition process toward sustainability. Diligent decisionmaking from an economic, environmental and social point of view when managing CMSs can act as inducers of changes in the organization's philosophy and values, awakening employees to reframe the value of their own work and products, thus improving the management of negative and positive impacts on environment and society (Jones and Corral de Zubielqui, 2017).

\section{Emphasis Measuring and Evaluating How Well an Organization's CMS Is Performing}

In the updating of the CMSs standards, greater emphasis on measuring and evaluating processes and results (inputs and outputs) contrasts with less emphasis on prescriptive requirements and documentation, such as documented procedures and a quality manual, which are no longer mandatory (Manders et al., 2016; Rybski et al., 2017). The emphasis on measuring and evaluating the processes and results of the CMSs helps the operationalization of the sustainability strategy, as it provides results that reflect the organization's performance in aspects of the environment, occupational health and safety, stakeholder satisfaction, among others important for evaluating the sustainability performance. An initial diagnosis can be carried out to identify the actions already implemented in the CMSs that contribute to the organization's SD in the TBL pillars. The actions in progress for development of the sustainability strategy need to be measured and managed with the same rigor as managing the quality of products and processes or any other important process for the organization. As this is a cross-cutting strategy that covers several sectors and departments, the participation of all employees is necessary so that the sustainability indicators and objectives are properly monitored and evaluated. The results of the CMSs measurement and evaluation actions can act as a bridge between the CMSs, the sustainability strategy and its effective implementation.

\section{Culture of Integration and Continuous Improvement}

Annex SL endorses the integration of the CMSs, ensuring that the revised and proposed standards by ISO from 2015 onwards are more compatible with regard to terms, definitions and requirements. This increased compatibility between standards favors dialogue between different areas of the organization, intensifying the exchange of knowledge and dialogue in favor of achieving common goals, such as economic, social, and environmental sustainability (Nunhes et al., 2020). As shown in Figure 2, Annex SL was developed based on Deming's PDCA cycle and its effective structuring started from section Conclusions. Sections 4 (context of the organization), 5 (leadership), 6 (planning), and 7 (support) are related to the concept "plan," section 8 (operation) is related to the concept "do," section 9 (performance evaluation) to the concept "check" and section 10 (improvement) to the concept "act" (Majerník et al., 2017; Nunhes et al., 2017).

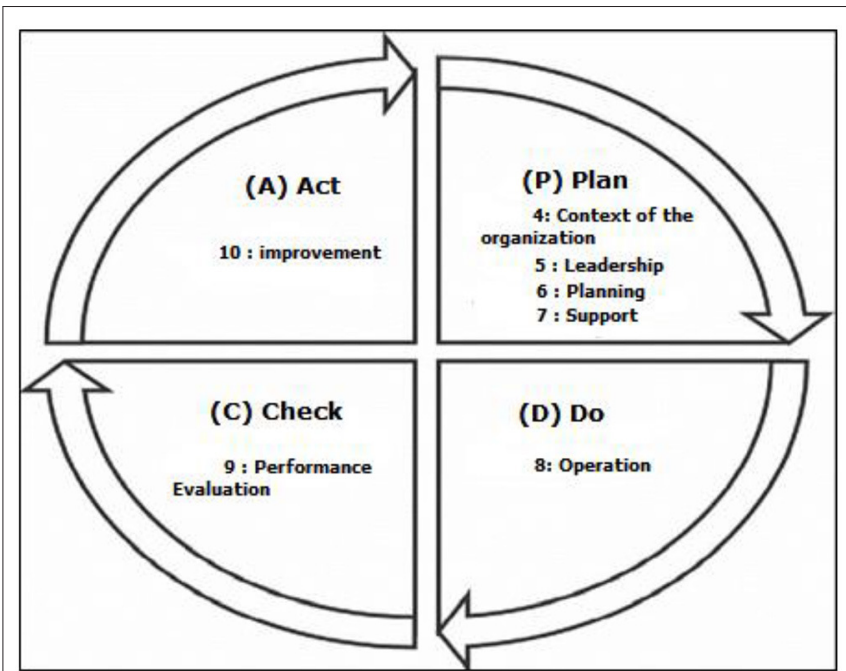

Source: Based on ISO, 2021

FIGURE 2 | Sections of the Annex SL in each phase of the PDCA cycle. Source: Based on ISO (2021).

The culture of continuous improvement suggested by ISO with the publication of Annex SL is also beneficial for the incorporation of sustainability in the tasks and routines of workers involved in CMSs, as it can awaken in these people the awareness of the importance of the sustainability strategy, highlighting the responsibilities and contributions of each one to achieve more sustainable results. Additionally, the SDCA cycle (Standard, Do, Check, Act) can help standardize good results, allowing for its consistent replication and leading to a reduction in variability between systems and a reduction in costs and waste. The culture of continuous improvement focused on the standardization of CMSs can support the development of sustainability management, helping, for example, in the creation of sustainability audit processes, management of sustainability processes and documents, sustainability performance assessment and continuous improvement of sustainability strategy.

\section{CONCLUSIONS}

The objective of this work was achieved by identifying the important contributions that the modifications of Annex SL brought to sustainability in companies that have implemented CMSs. The main identified contributions of the HLS to sustainability are organizational context analysis, risk management, evidence-based decision making, emphasis on measuring and evaluating processes and results, and a culture of integration and continuous improvement. The inclusion of the requirement to analyze the organizational context in the scope of the CMSs is one of the contributions identified, as it allows managers to periodically update themselves by providing important information that will support the analyses of sustainability performance. Another contribution is the inclusion of the risk-based thinking, which enables the analysis, 
treatment and mitigation of economic, environmental, and social risks. The integrated analysis of these risks in the context of CMSs can promote a more balanced development between the TBL pillars through the elaboration of an action plan that reduces the identified risks. Evidence-based decision making is a contribution of Annex SL that can induce positive paradigm shifts that contribute to the creation of a more sustainable organizational culture. In this way, evidence-based decision making that contributes to the development of sustainability is a process of change that begins with senior management and must be extended to other levels of the company, re-signifying the value of the work of all those involved and promoting sustainability culture.

The need for greater emphasis on measuring and evaluating the processes and results of the CMSs is also a contribution of Annex SL to sustainability, as it provides results that reflect the organization's performance in aspects of the environment, occupational health and safety, and stakeholder satisfaction, among others important for evaluating the sustainability performance. Finally, the promotion of a culture of integration and continuous improvement benefits the development of sustainability in the tasks and routines of workers involved

\section{REFERENCES}

Aboelmaged, M. (2018). The drivers of sustainable manufacturing practices in Egyptian SMEs and their impact on competitive capabilities: a PLS-SEM model. J. Clean. Prod. 175, 207-221. doi: 10.1016/j.jclepro.2017.12.053

Anttila, J., and Jussila, K. (2017). ISO 9001:2015 - a questionable reform. What should the implementing organisations understand and do? Total Qual. Manag. Busin. Excell. 28, 1090-1105. doi: 10.1080/14783363.2017.1309119

Benyettou, S., and Abdellatif, M. (2018). Empirical study on the integrated management system in Algerian companies. J. Ind. Eng. Manag. 11:135. doi: $10.3926 /$ jiem. 2445

Chiarini, A. (2017). Risk-based thinking according to ISO 9001:2015 standard and the risk sources European manufacturing SMEs intend to manage. TQM J. 29, 310-323. doi: 10.1108/TQM-04-2016-0038

Dahlin, G., and Isaksson, R. (2017). Integrated management systems - interpretations, results, opportunities. TQM J. 29, 528-542. doi: 10.1108/TQM-01-2016-0004

Domingues, J. P. T., Sampaio, P., and Arezes, P. M. (2015). Analysis of integrated management systems from various perspectives. Total Qual. Manag. Busin. Excell. 26, 1311-1334. doi: 10.1080/14783363.2014.931064

Ferreira, C., Dos, S., Poltronieri, C. F., and Gerolamo, M. C. (2019). ISO 14001:2015 and ISO 9001:2015: analyse the relationship between these management systems standards and corporate sustainability. Gestão Prod. 26:4. doi: 10.1590/0104-530x3906-19

Fonseca, L., and Domingues, J. (2017). ISO 9001:2015 edition- management, quality and value. Int. J. Qual. Res. 11, 149-158. doi: 10.18421/IJQR11.01-09

Fonseca, L., and Domingues, J. (2018). Exploratory research of ISO 14001:2015 transition among Portuguese Organizations. Sustainability 10:781. doi: $10.3390 /$ su10030781

Fonseca, L. M. (2015). From quality gurus and TQM To ISO 9001:2015: a review of several quality Paths. Int. J. Qual. Res. 9, 167-180. Available online at: http:// www.ijqr.net/journal/v9-n1/12.pdf (accessed October 7, 2021).

Hammer, J., and Pivo, G. (2017). The triple bottom line and sustainable economic development theory and practice. Econ. Dev. Q. 31, 25-36. doi: 10.1177/0891242416674808

Hsu, C.-H., Chang, A.-Y., and Luo, W. (2017). Identifying key performance factors for sustainability development of SMEs - integrating QFD and fuzzy MADM methods. J. Clean. Prod. 161, 629-645. doi: 10.1016/j.jclepro.2017.05.063 in the CMSs, as it allows workers to be aware of sustainable development through the enhancement of dialogue and communication between different areas. Future studies can continue this line of research (Annex SL, CMSs, and Sustainability), empirically verifying the findings of this study and exploring other possible contributions of Annex SL to sustainability.

\section{AUTHOR CONTRIBUTIONS}

All authors listed have made a substantial, direct and intellectual contribution to the work, and approved it for publication.

\section{FUNDING}

This study was funded in part by the Coordenação de Aperfeiçoamento de Pessoal de Nível Superior-Brazil (CAPES)-Code 001, CNPq-Conselho Nacional de Desenvolvimento Científico e Tecnológico (Grant number 312538/2020-0), and the Fundação de Amparo à Pesquisa do Estado de São Paulo (Grant numbers 2016/20160-0, 2017/18304-7, 2018-17537-0, and 2019/08750-5).

Ikram, M., Zhang, Q., Sroufe, R., and Ferasso, M. (2021). Contribution of certification bodies and sustainability standards to sustainable development goals: an integrated grey systems approach. Sustain. Prod. Consumpt. 28, 326-345. doi: 10.1016/j.spc.2021.05.019

Ismyrlis, V., and Moschidis, O. (2015). The effects of ISO 9001 certification on the performance of Greek companies. TQM J. 27, 150-162. doi: 10.1108/TQM-07-2013-0091

ISO (2021). Annex SL (normative) Harmonized Approach for Management System Standards. ISO/IEC Directives, Part 1. Available online at: https://www.iso.org/ sites/directives/current/consolidated/index.xhtml (accessed October 7, 2021).

Johnson, M. P., and Schaltegger, S. (2016). Two decades of sustainability management tools for SMEs: how far have we come? J. Small Busin. Manag. 54, 481-505. doi: 10.1111/jsbm. 12154

Jones, J., and Corral de Zubielqui, G. (2017). Doing well by doing good: a study of university-industry interactions, innovationess and firm performance in sustainability-oriented Australian SMEs. Technol. Forecast. Soc. Change 123, 262-270. doi: 10.1016/j.techfore.2016.07.036

Kafel, P. (2016). The place of occupational health and safety management system in the integrated management system. Int. J. Qual. Res. 10, 311-324. doi: 10.18421/IJQR10.02-05

Klute-Wenig, S., and Refflinghaus, R. (2015). Integrating sustainability aspects into an integrated management system. TQM J. 27, 303-315. doi: 10.1108/TQM-12-2013-0128

Lalonde, C., and Boiral, O. (2012). Managing risks through ISO 31000: a critical analysis. Risk Manag. 14, 272-300. doi: 10.1057/rm.2012.9

Lopez-Cabrales, A., and Valle-Cabrera, R. (2020). Sustainable HRM strategies and employment relationships as drivers of the triple bottom line. Hum. Resour. Manag. Rev. 30:100689. doi: 10.1016/j.hrmr.2019.1 00689

Lozano, S. (2015). A joint-inputs Network DEA approach to production and pollution-generating technologies. Expert Syst. Appl. 42, 7960-7968. doi: 10.1016/j.eswa.2015.06.023

Majerník, M., Daneshjo, N., Chovancová, J., Sančiová, G. (2017). Design of integrated management systems according to the revised iso standards. Pol. J. Manag. Stud. 15, 135-143. doi: 10.17512/pjms.2017.15.1.13

Manders, B., Vries, H. J., and Blind, K. (2016). ISO 9001 and product innovation: a literature review and research framework. Technovation 48-49, 41-55. doi: 10.1016/j.technovation.2015.11.004 
Moumen, M., and Elaoufir, H. (2018). An integrated management system: from various aspects of the literature to a maturity model based on the process approach. Int. J. Prod. Qual. Manag. 23:218. doi: 10.1504/IJPQM.2018.089157

Nunhes, T. V., Bernardo, M., and Oliveira, O. J. (2019). Guiding principles of integrated management systems: towards unifying a starting point for researchers and practitioners. J. Clean. Prod. 210, 977-993. doi: 10.1016/j.jclepro.2018.11.066

Nunhes, T. V., Bernardo, M., and Oliveira, O. J. (2020). Rethinking the way of doing business : a reframe of management structures for developing corporate sustainability. Sustainability (Switzerland) 12:1177. doi: 10.3390/su12031177

Nunhes, T. V., Motta Barbosa, L. C. F., and Oliveira, O. J. (2017). Identification and analysis of the elements and functions integrable in integrated management systems. J. Clean. Prod. 142, 3225-3235. doi: 10.1016/j.jclepro.2016.10.147

Olechowski, A. J., Oehmen, W., and Seering, and, M., Ben-Daya (2016). The professionalization of risk management: what role can the ISO 31000 risk management principles play? Int. J. Project Manag. 34, 1568-1578. doi: 10.1016/j.ijproman.2016.08.002

Oliveira, O. J. (2013). Guidelines for the integration of certifiable management systems in industrial campanies. J. Clean. Prod. 57, 124-133. doi: 10.1016/j.jclepro.2013.06.037

Purwanto, A., Sulistiyadi, A., Primahendra, R., Kotamena, F., Prameswari, M., and Ong, F. (2020). Does quality, safety, environment and food safety management system influence business performance? Answers from indonesian packaging industries. Int. J. Control Autom. 13, 22-35.

Ribeiro, F., Santos, G., Rebelo, M. F., Silva, R. (2017). Integrated Management Systems: trends for Portugal in the 2025 horizon. Proc. Manuf. 13, 1191-1198. doi: 10.1016/j.promfg.2017.09.194

Rybski, C., Jochem, R., and Homma, L. (2017). Empirical study on status of preparation for ISO 9001:2015. Total Qual. Manag. Busin. Excell. 28, 1076-1089. doi: 10.1080/14783363.2017. 1303886

Sajan, M. P., Shalij, P. R., Ramesh, A., and Biju, A. P. (2017). Lean manufacturing practices in Indian manufacturing SMEs and their effect on sustainability performance. J. Manuf. Technol. Manag. 28, 772-793. doi: 10.1108/JMTM-12-2016-0188

Savino, M. M., and Batbaatar, E. (2015). Investigating the resources for Integrated Management Systems within resource-based and contingency perspective in manufacturing firms. J. Clean. Prod. 104, 392-402. doi: 10.1016/j.jclepro.2015.04.115

Sharma, N. K., Govindan, K., Lai, K. K., Chen, W. K., and Kumar, V. (2021). The transition from linear economy to circular economy for sustainability among SMEs: a study on prospects, impediments, and prerequisites. Busin. Strategy Environ. 30, 1803-1822. doi: 10.1002/bse.2717

Skład, A. (2019). Assessing the impact of processes on the Occupational Safety and Health Management System's effectiveness using the fuzzy cognitive maps approach. Saf. Sci. 117, 71-80. doi: 10.1016/j.ssci.2019.03.021

Stefaniec, A., Hosseini, K., Xie, J., and Li, Y. (2020). Sustainability assessment of inland transportation in China: a triple bottom line-based network DEA approach. Transp. Res. Part D. 80:102258. doi: 10.1016/j.trd.2020.102258

Susanto, A., and Mulyono, N. (2017). The transitional change on the implementation of iso 14001:2015 in copper ore mill - case study. J. Ecol. Eng. 18, 37-49. doi: 10.12911/22998993/76210

WCED (1988). World Comission on Environment and Development: Our Common Future. Available online at: https://sustainabledevelopment.un.org/content/ documents/5987our-common-future.pdf (accessed October 7, 2021).

Conflict of Interest: The authors declare that the research was conducted in the absence of any commercial or financial relationships that could be construed as a potential conflict of interest.

Publisher's Note: All claims expressed in this article are solely those of the authors and do not necessarily represent those of their affiliated organizations, or those of the publisher, the editors and the reviewers. Any product that may be evaluated in this article, or claim that may be made by its manufacturer, is not guaranteed or endorsed by the publisher.

Copyright (C) 2021 Nunhes, Campos, Francisco and Oliveira. This is an open-access article distributed under the terms of the Creative Commons Attribution License (CC $B Y)$. The use, distribution or reproduction in other forums is permitted, provided the original author(s) and the copyright owner(s) are credited and that the original publication in this journal is cited, in accordance with accepted academic practice. No use, distribution or reproduction is permitted which does not comply with these terms. 